emerald International Journal of Building Pathology and Adaptation
PUBLISHING

\title{
Advancing Real Estate Decision Making: Understanding Known, Unknown and Unknowable Risks
}

\begin{tabular}{|r|l|}
\hline Journal: & International Journal of Building Pathology and Adaptation \\
\hline Manuscript ID & IJBPA-01-2018-0006.R1 \\
\hline Manuscript Type: & Original Article \\
\hline Keywords: & $\begin{array}{l}\text { Real Estate Risk Management, Extreme Risk Events, Real Estate } \\
\text { Performance, Risk Management Framework }\end{array}$ \\
\hline \multicolumn{2}{|l}{} \\
\hline
\end{tabular}

\section{SCHOLARONE ${ }^{\text {m }}$ \\ Manuscripts}




\section{ADVANCING REAL ESTATE DECISION MAKING: UNDERSTANDING KNOWN, UNKNOWN AND UNKNOWABLE RISKS}

\section{$1.0 \quad$ Introduction}

The word 'risk' originated from the early Italian risicare which means 'to dare'. In this sense, risk is a choice of actions we dare to take. Since the beginning of recorded history, gambling is the very essence of risk taking that breaks through into the laws of probability. Whereas the modern concept of risk is rooted in the Hindu-Arabic numbering system, the academic study of risk initiated during the Renaissance. Until human discovered established risk boundaries, the future was a mirror of the past. Hence, the radical idea that defines the boundary between the past and the modern is the mastery of risk (Bernstein 1996).

Modern risk theory is grounded in the literature concerned with known outcomes and probabilities whereas the uncertainty means known outcomes but unknown probabilities. Risks can occur in either tails of an empirical distribution but the downside risk associated with the lower tail is the main focus in risk management literature (Granger 2010). On a holistic perspective, there are four important points to remember in dealing with risk, namely:

i) Probability that an event will occur.

ii) Event and its nature.

iii) Consequences of that event.

iv) Period of exposure to the event (and to its consequences if that is also relevant).

Source: Edwards and Bowen 2013 p.11

Furthermore, Edwards and Bowen (2013) explained, it is hard to draw a clear distinction between risk and uncertainty. In a two-tailed risk definition, the risk is equated with uncertainty as in "if there is uncertainty there must be risk". If the downside risk definition is used then the statement becomes "if there is risk there must be uncertainty, but if there is uncertainty there need not be risk" (Granger 2010 p.42). In simple terms, uncertainty involves unknowns with no measurable probability of outcome as compared to the 'known' properties of risk. 
The introduction of probability in the definition of risk automatically implies its evaluation. The deconstruction of model/data dichotomy into its constituent parts: model/no model, data/no data can be used to analyse risks in various situations (O'Roarty 2005). Likewise, Diebold et al (2010) skilfully conceptualised the downside risks into Known $(\mathrm{K})$, the unknown $(\mathrm{u})$ and the Unknowable $(\mathrm{U})$ risk categories based on model/data dichotomy developed on the grounds of both empirical and methodological knowledge.

The $\mathrm{K}$ event is where it is known what could happen and when, eg the Year 2000 computer bug. These events can be measured and the disruption (worst case) forecast. For u events, these may be quantifiable even though it may not be known when they will occur e.g. earthquakes. The $U$ event is difficult, if not impossible, to model. It is hard to imagine what kinds of event might fit into this category i.e. asteroids colliding with earth (Higgins and Perera 2016).

Bringing forth different authors' interpretations on $\mathrm{KuU}$, this research paper aims to conceptualise known-unknown risks with reference to applications in a real estate environment. In developing a conceptual framework, key factors, constructs or variables with recognised relationships can be established and described in-depth (Miles et al 2013).

Following this introduction, Section Two provides a framework for defining KuU risks. Section Three looks at knowledge as a theory and measurement in order to classify $\mathrm{KuU}$ risks in the model/data dichotomy. This is followed by Section Four which addresses the knowledge transition from $U$ to $\mathrm{K}$ with the availability of models and data. This is then extended in Section Five by analysing the impact of KuU risks on the real estate environment by linking the concepts to real estate strategies. The last section provides the concluding remarks.

\subsection{KuU Event Framework}

The knowns and unknowns is a famous adage from former U.S. Defence Secretary Donald Rumsfeld in response to a question raised at the U.S. Department of Defence news briefing on February 12, 2002 about the lack of evidence of the supply of weapons of mass destruction to terrorist groups. According to Rumsfeld, there exist three forms of knowledge and non-knowledge associated with risk. It is useful to categorise future risks into three main groups: known (K) risk, the unknown (u) risk and the unknowable $(U)$ risk and alternately termed in different ways: known as known knowns, known unknowns and unknown unknowns; white swans, grey swans and Black Swans respectively (Casti 2011, Daase and Kessler 2007, Diebold et al. 2010, Sikich 2010). Out of them, Black Swan is a popular term in risk management made famous by Nassim Nicholas Taleb, which has triplet characteristics: extreme impact, rarity and retrospective predictability. It is instructive to examine each of the $\mathrm{KuU}$ categories and match them up with real estate situations.

\subsection{Known Risks (Known Knowns) - K}

The risks associated with $\mathrm{K}$ can be measured and disruption forecasted. The corresponding co-risks will usually have been established from prior experience and their usefulness will be understood and appreciated (Granger 2010). According to Sikich (2010) these events can occur as a result of short-sightedness. For example, 
urbanisation, the rise of global middle class, shift of economic power to developing countries, ageing demographics and global interconnectedness are demographic related known risks in the real estate frontier.

The dynamical models with the use of tools from applied mathematics and computational analysis effectively address many questions of practical concern such as the theory of chaotic dynamical systems. In another direction, network analysis gives the possibility for understanding the deep connective structure of systems, and to identify pressure points in that structure whose removal could lead to catastrophic systemic collapse (Casti 2011). For instance, real estate in developing countries is skewed in favour of the $\mathrm{K}$ risk knowledge, primarily because of limited local historical event data and the focus on comparative market performance benchmarks.

\subsection{Unknown Risks (Known Unknowns) - u}

This type of $u$ event is certainly the most commonly encountered situation but the extent and full implications remain unclear due to the lack of ex-ante judgement. These events may be quantifiable but the time of occurrence is unknown. However, there are events where the location, timing and extent of the event are difficult to quantify (Granger 2010). Possible illustrations are a virus that evolves into a new and unexpected form, a natural event of an unusually large magnitude in a location where it is not expected. For example, in real estate, natural disasters (tsunami, earthquakes, hurricane, volcanic eruption) or a new virulent form of computer virus can be quantifiable even though we may not know when they will occur.

'Perfect storm' is another term used to describe u risks, which are mostly aleatory uncertainties (randomness) in conjunctions of rare but known events. An example is a devastating storm in the northern Atlantic that caught some boats by surprise and killed 12 people in October 1991. It was the result of a conjunction of a storm that started over the USA, a cold front coming from the North, and the tail of a tropical storm coming from the South. All three types were known before and occur regularly, but their conjunction is very rare (Paté-Cornell 2012).

There is a lot of measured real estate associated data which requires processes using statistical and actuarial techniques to either construct a model that fits the data or to be able to infer what is more or less likely to turn up at the next observation. For example: severe weather events and real estate structures. The important point to note about this real estate uncertainty is that the weather data is generally aggregated and is processed without benefit of any underlying dynamical model.

\subsection{Unknowable Risks (Unknown Unknowns) - U}

This is the risk associated with a $U$ event which is difficult, if not impossible, to model due to lack of knowledge in hand. This includes all the risks that cannot be identified in advance. No probabilities can be specified for some or all events and no realistic boundaries can be stated for the consequences. An example is part of a comet striking the earth, alien invasion, grey goo catastrophe (hypothetical world's end scenario involving molecular nanotechnology). The science fiction shelf is littered with imaginative scenarios for how this type of global shock might take place. In recognising the $U$ category, it is worth pointing out that if an event occurs, the level of awareness afterwards can be included in the $u$ category and so some form of 
provision/adjustment can be made in future decisions (Casti 2011, Granger 2010, Makridakis et al. 2009, Taleb 2008).

\subsection{Unknown Known Risks}

Defence Secretary Donald Rumsfeld conceals the fourth category which is 'unknown knowns'. These are the risks which are deliberately forgotten, suppressed or repressed. This type of uncertainty is quantifiable but without data available to authenticate or substantiate. The resolution of this uncertainty rests in the distinction between implicit versus explicit knowledge. Methodological tools are available to bring out emergent properties with a set of background assumptions (Casti 2011, Daase and Kessler 2007). A particular scenario of the world 2020 can be adopted for a real estate example. One possibility is artificial intelligence providing autonomous driverless cars. The simulation may produce unexpected consequences on real estate as autonomous cars with self-parking systems will likely not require defined car parking spaces and so ultimately change the urban landscape.

\subsection{KuU Knowledge as Measurement and as Theory}

The introduction of probability in the definition of risk automatically implies its evaluation, which can be done only with relevant data. The deconstruction of model/data dichotomy into its constituent parts: model/no model, data/no data can be used to analyse risks in various property situations (O'Roarty 2005). The aforementioned four classes of uncertainties are summarised in Table 1 along with the possible models/data combination and methodologies appropriate to each category. These elements can then form the backbone of any scientific study of the unknown.

\begin{tabular}{|c|c|c|c|}
\hline & \multicolumn{2}{|c|}{ Empirical Knowledge } \\
\hline & & Data & No data \\
\hline \multirow{2}{*}{ 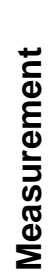 } & Model & $\begin{array}{l}\text { Known knowns - Threat } \\
\text { (dynamic system theory; network } \\
\text { analysis) }\end{array}$ & $\begin{array}{l}\text { Unknown knowns - Risk } \\
\text { (simulation) }\end{array}$ \\
\hline & $\begin{array}{c}\text { No } \\
\text { model }\end{array}$ & $\begin{array}{l}\text { Known unknowns - Ignorance } \\
\text { (statistical techniques) }\end{array}$ & $\begin{array}{l}\text { Unknown unknowns - Disaster } \\
\text { (imagination and scenarios/stories) }\end{array}$ \\
\hline
\end{tabular}

Table 1: Model/ Data Dichotomy of Four Classes of Uncertainties

Source: Casti 2011; Daase and Kessler 2007

Since knowledge is both measurement and theory, the KuU paradigm can be envisioned as a measurement and as a theory as given in Table 1 . Knowledge as measurement focusses on measuring possible outcomes with associated probabilities while knowledge as theory focusses on the conceptual model that helps to understand the underlying structure of the phenomenon. These two are mutually reinforcing uncertainty pillars as better measurement provides the grist for the theory mill whereas better theory stimulates improved measurement (Diebold et al. 2010).

To understand the different classes of uncertainties, current events can provide examples where possible measurement and theory knowledge can provide improved 
outcomes. In residential real estate, recent central bank policies are highly accommodative towards credit markets which have provided unprecedented capital growth in many housing markets. The supply of mortgage credit in the housing market is a risk which can challenge the dichotomy of measurement and theory where the affect, is to an extent an unknown, and pre-existing local housing market information is currently contemporaneous in context to the monetary markets.

Better measurement in part means better data. Data can be obtained through more precise and timely measurement of previously measured phenomena, correspond to intrinsically new data about the phenomena that previously did not exist, technological advances in data capture, transmission and organisation. However, better data in dealing with $U$ is necessarily much more a conjecture. Yet, the collection and analysis of data regarding near misses that were narrowly forefended and may provide into the domain of $U$ and alternative outcomes (Diebold et al. 2010).

\subsection{Knowledge Transition}

With the understanding of $\mathrm{KuU}$ risks in their theoretical perspective, Figure 1 illustrates a schematic classification under sub-layers with respect to empirical knowledge by means of the availability of existing literature; methodological knowledge with regard to the quantification by assigning probabilities; impact across the timeline and finally the level of awareness.

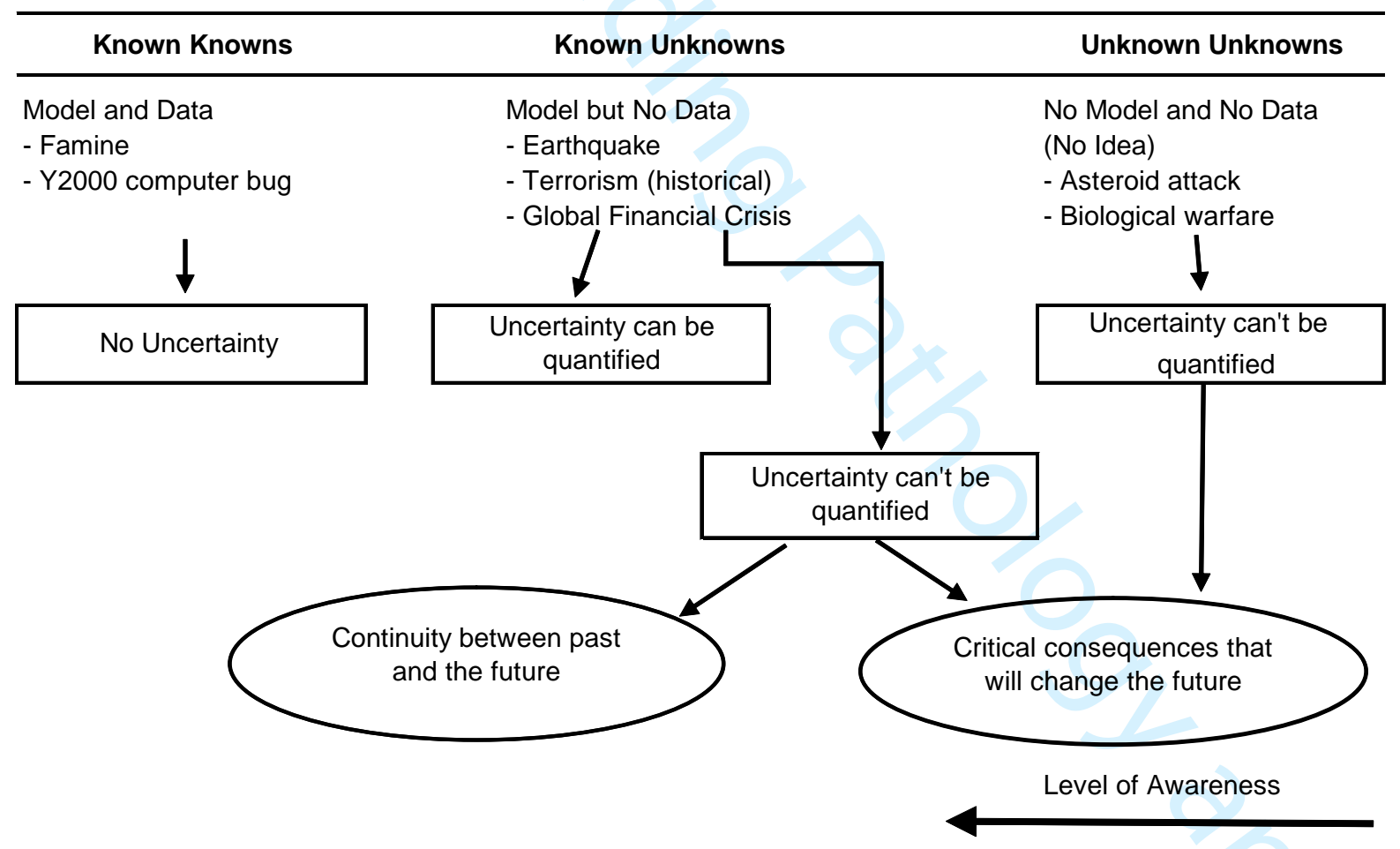

Figure 1: Distinguishing the Knows and Unknowns Event Framework Source: Higgins and Perera 2016

In defining these categories, relevant information can be sourced on known known events for decision-making purposes. This compares to unknown unknown events, which are difficult for individuals to even identify and therefore quantify. This leaves the known unknown category, where there is known information although there 
needs to be corporate real estate strategies alongside the development of probability theory, as past events may be random and vary in magnitude, for example: building surveillance to foil possible terrorist plots (Evan 2012).

As Figure 1 depicts the knowledge transits with the increasing level of awareness from total ignorance to determinism. When the data is available for $U$ events then it transits to the simple $u$ category, further with the development of models, the knowledge subsequently transits to the known category.

A similar illustration is made available by Snowden (2003) with the Cynefin framework which has four quadrants to explain complex social environments: simple, complicated, complex and chaotic, as shown Figure 2. With the availability of empirical and methodological knowledge, knowledge transits from $U$ to $u$ then to knowable and finally to $\mathrm{K}$. However, the obvious domain is next to Chaos, because the extreme obviousness easily produces catastrophic failure. Thus, the boundary is represented by a cliff. Therefore, the transition from $\mathrm{K}$ to $\mathrm{U}$ is like falling off the cliff due to loss of control.

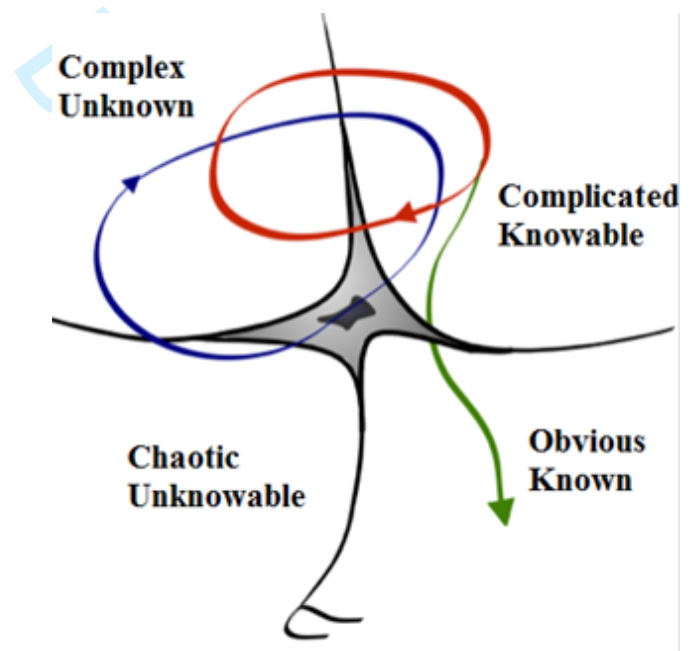

\section{Figure 2: Cynefin Framework}

\section{Source: Snowden 2003}

The existing risk management theories and the decision-making drivers can focus almost exclusively on known risk. However, a large fraction of real-world risk management challenges falls in the domain of unknown category. Both Bralver and Borge (2010) and Diebold et al. (2010) believed that known situations are often of relevance, but the most present risks ranged from uncertain to $U$ which brought forward the attention to the uncertainty. In a real estate context, known risks like flooding and terrorism although somewhat difficult to entertain can be planned for and managed, it is the unknown possibilities associated with events like pandemics which can leave organisations vulnerable. Testing and research are generic measures to meet this type of $U$ event. Consequently, the level of awareness has been increased and such events are included in the known unknown category. 


\subsection{KuU Risks in Real Estate}

The performance of any property cannot be judged without assessing the risks. The sectoral linkage of commercial real estate characterises its risk profile, dynamic profile of uncertainty, and the composition of $\mathrm{K}, \mathrm{u}$ and $\mathrm{U}$ as unique across the spectrum of asset classes (Bardhan and Edelstein 2010). However, the pricing of property is based on conventional property valuation techniques as risks are commonly pooled to provide a measurement of value. Thus, property valuation techniques fail to notice K, $\mathrm{u}$ and $\mathrm{U}$ risks separately (Higgins 2015).

The uncertainty, risk profile and the knowability of real estate are dependent on the uncertainty of the mix of factors. Figure 3 provides an overview of the thematic classification of KuU risks in real estate. The real estate outcomes are determined by a number of economic and non-economic factors as featured below.

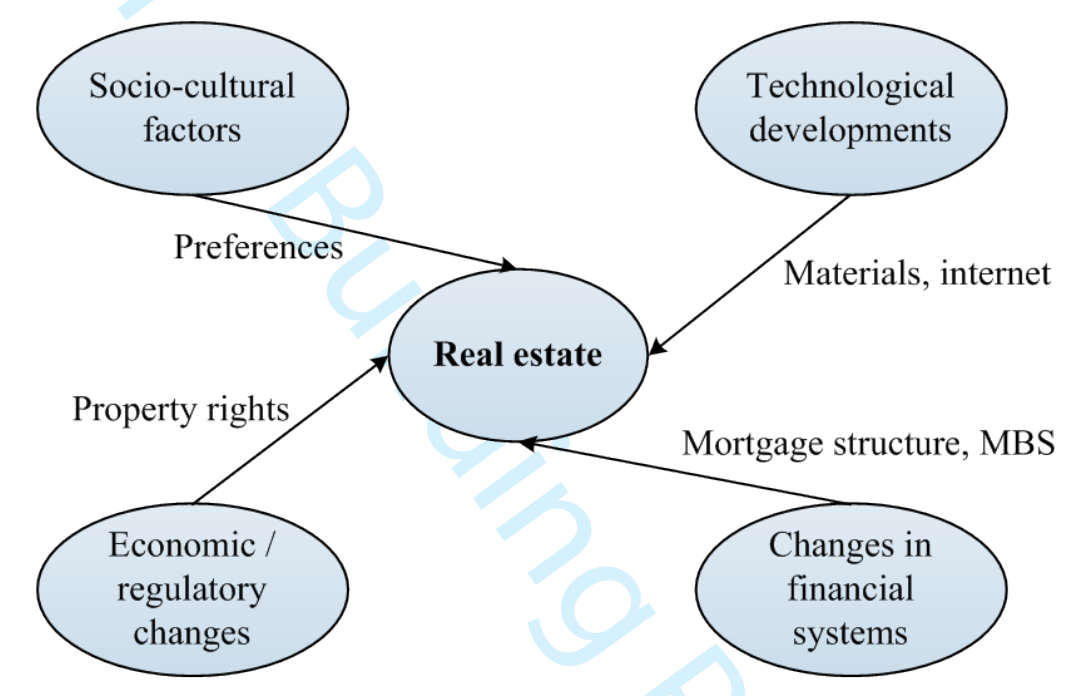

Figure 3: Framework for Analysing KuU in Real Estate

Source: Bardhan and Edelstein 2010 p.147

According to Bardhan and Edelstein (2010), the historical background of KuU real estate frontier highlights how several non-economic sources of uncertainty have interacted with the real estate market and driven into major changes as demonstrated by following examples:

i) The development of property rights for land created the first defensible property and marks an influential moment in real estate markets.

ii) Socio-cultural developments intricately intertwined with the demand for land such as unforeseeable situations include the massive rural-urban migration, the changing feudal structure and industrial capitalism.

iii) The evolution of the structure of family and the household has been the source of unexpected change in real estate market.

iv) The creation of specialised real estate brought about by the rise of professionalization as well as by organisational imperatives.

v) Technological advances have also altered the uncertainty frontier such as the development of new material and advanced engineering techniques.

vi) New fields of finance lead to the emergence of innovative finance, including real estate finance creating an uncertain change in real estate performance. 
The following Table 2 summarises Bardhan and Edelstein (2010) elements of uncertainty on real estate and classifying them by examples into the KuU framework. A mere overview of Table 2 shows that a few groups of uncertainties are known in terms of future evolution and possible impact on real estate. Although, real world challenges are at the other end of the spectrum towards uncertainty.

\begin{tabular}{|c|c|c|c|}
\hline KuU Event Examples Creating Real Estate Uncertainty & K & $\mathbf{u}$ & $\mathbf{U}$ \\
\hline \multicolumn{4}{|l|}{ Social-cultural factors } \\
\hline - Migration by populations & $\sqrt{ }$ & $\sqrt{ }$ & \\
\hline - Cultural shocks (land conflicts, religious disputes) & $\sqrt{ }$ & $\sqrt{ }$ & \\
\hline - Environmental and natural catastrophic issues (pandemics) & & $\sqrt{ }$ & $\sqrt{ }$ \\
\hline \multicolumn{4}{|l|}{ Technological developments } \\
\hline - $\quad$ Digital environment (cyber-attacks) & & $\sqrt{ }$ & $\sqrt{ }$ \\
\hline - $\quad$ Artificial intelligence (autonomous weapons) & & $\sqrt{ }$ & $\sqrt{ }$ \\
\hline - $\quad$ Biological science (genetically modified crops) & $\sqrt{ }$ & $\sqrt{ }$ & \\
\hline \multicolumn{4}{|l|}{ Changes in financial systems } \\
\hline - Innovative investment products (complex derivatives) & $\sqrt{ }$ & $\sqrt{ }$ & $\sqrt{ }$ \\
\hline - Global capital markets (currency crisis) & & $\sqrt{ }$ & $\sqrt{ }$ \\
\hline - Capital market legislation (liquidity and capital adequacy risk) & & $\sqrt{ }$ & $\sqrt{ }$ \\
\hline \multicolumn{4}{|l|}{ Economic/regulatory changes } \\
\hline - Anti-bribery and corruption policies & $\sqrt{ }$ & $\sqrt{ }$ & \\
\hline - $\quad$ Resource scarcity (water security) & $\sqrt{ }$ & $\sqrt{ }$ & $\sqrt{ }$ \\
\hline - $\quad$ Asset bubbles (housing markets) & & $\sqrt{ }$ & $\sqrt{ }$ \\
\hline
\end{tabular}

Table 2: KuU Events Impacting on Real Estate Uncertainty

In many instances, the science of evaluating Table 2 risks is in the unknown category, since many of the probabilities are unknown. For example, changing population factors includes socio-cultural trends which are often within defined boundaries i.e. immigration quotas. Thus, a number of demographic related risk drivers may be foreseeable to a certain extent and can be categorised under $\mathrm{K}$ but given the room for $u$ category (mass immigration). With the advancement of geological sciences, environmental parameters become apparent but timing and magnitude remains unclear. Further, there may be new forms of unknowable futures without any prior evidence.

Globalisation is a driver of the real estate economy with increasing economic and financial integration whilst brings an elevated risk of contagion. For example, global financial markets can be a known space influenced on local real estate markets. Likewise, global sourcing of industrial supply chains can impact on the demand for real estate space as with increased interconnectedness with technology (ecommerce, internet shopping) can create $u$ and perhaps $U$ nature as to unknown interactions of factors in an unpredictable form.

Real estate assets are characterised by lumpiness and illiquidity. The Global Financial Crisis (GFC) of 2007-2009 has increased liquidity risk and credit default. Knowing the characteristics of real estate assets, the structure of real estate transactions can move from the realm of $\mathrm{K}$ to $\mathrm{u}$ and even to the $\mathrm{U}$. One of the most significant macroeconomic medium that affects real estate is through the credit market via interest rate movements. The impact is significant due to higher gearing 
levels which significantly add to the cost of capital. A housing bubble burst is an example of a $u$ to $U$ event, with low probability but with extremely high impact which may not be unable to capture through mathematical modelling.

Incorrect assessment of prepayments by mortgage borrowers can lead to cash flow volatility and uncertainty in the mortgage security market. KuU is a renewal process by which transits from uncertainties to a better understanding of prepayment behaviour driven by previous level of knowledge about prepayment risk. Further, government interventions have an impact on the real estate market including local rent control regulations and tax laws.

Higgins (2015) categorised the impact of $u$ risks related to the impact on real estate place/location and space/operation. Firstly, place risks (earthquakes, hurricanes, and severe weather) can damage physical buildings. Secondly, the space risk (global financial crisis, cyber-attacks) associated with the economic loss for the space occupier that may spread across several unrelated locations. Therefore, real estate decision should incorporate sufficient understanding of possible occurrences of known-unknown events to make viable corporate real estate decisions.

\subsection{KuU Risk Management}

Successful risk management requires constant review of the KuU which can promote improved decision making. Decision makers implicitly or explicitly assess $\mathrm{K}, \mathrm{u}$ and as much of $U$ as possible. Implicit risk assessment based on decision makers' intuition but the field of risk assessment usually is better to be explicit and as logical as possible. They have to act upon their beliefs about all the important variables, not just the hard facts known to them (Bralver and Borge 2010, Diebold et al. 2010). Figure 4 illustrates decision maker's imperatives towards assessing the risks. The three broad categories of KuU are divided into six distinct types. Decision makers convert them all into assessed risks with identified events and assigned probabilities. (Bralver and Borge 2010). 
Types of Risks

Examples

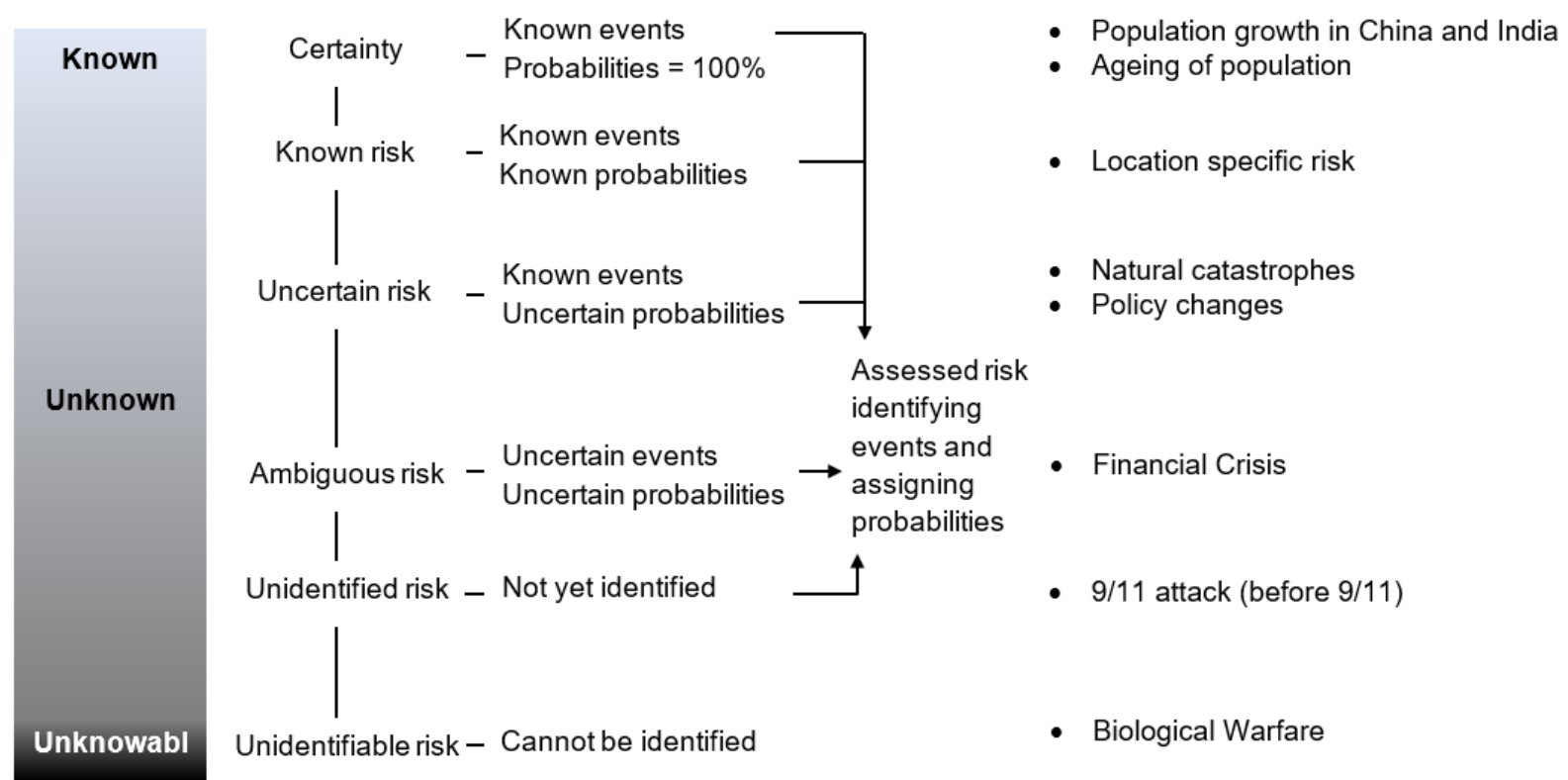

Figure 4: KuU and the Decision Maker's Imperative Adapted: Bralver and Borge 2010

This assessment can be achieved through 'reference class forecasting' a method based on the Nobel Prize winning work of Daniel Kahneman and Amos Tversky. This technique takes into account the outcomes of similar projects conducted in other organisations (Buhl 2012, Flyvbjerg and Budzier 2011).

In another perspective, Snowden (2003) mapped four different new approaches in the Cynefin framework to decision making in complex social environments as before mentioned in Section 4. The proposed decision making strategies are summarised below.

i) Simple/Known >> Sense, Categorize and Respond >> Best Practice.

ii) Complicated/ Knowable >> Sense, Analyse and Respond $>>$ Good Practice.

iii) Complex $>>$ Probe, Sense, Respond $>>$ Emergent Practice.

iv) Chaotic $\gg$ Act, Sense, Respond $\gg>$ Novel Practice.

However, according to Taleb et al. (2008), instead of trying to anticipate these uncertain events, the most appropriate response is to reduce the vulnerability to them. Risk management should be about lessening the impact of these events instead of engineered solutions which perpetuate illusions of human control over the environment.

In a risk-prone environment, a mechanism to identify, model and manage random events; unpredictable shocks and volatility, is a key requirement in real estate decision making. The focus on knowledge leads to a situation beyond a certain preset threshold to improved agility and reduced vulnerability towards unpredictable major events. Figure 5 represents a schematic model to categorise KuU events with the potential real estate strategy response. 


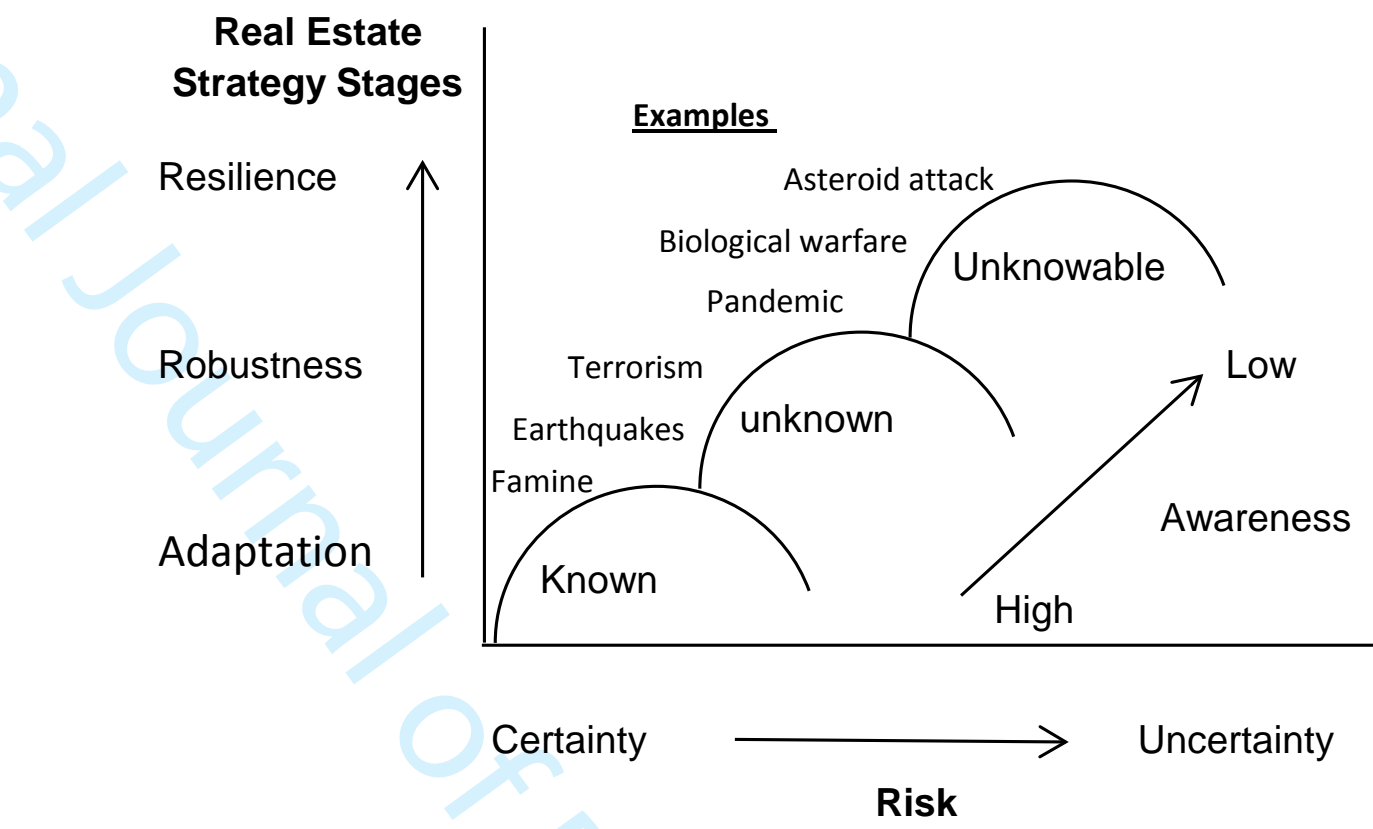

Figure 5: KuU Events and Real Estate Strategies

Figure 5 places the low predictability, high-impact events into arrange of KuU risk categories alongside detailing staged strategies for inclusion in the real estate decision making process. A systematic and broad guide to non-predictive decision making under uncertainty can be detailed with real estate operational examples as follows:

i) Adaptation: change the policy in response to the change in conditions. Designing for real estate flexibility: Rearrangement of global real estate organisations structure and efficiency brings the workplace flexibility through modularity, agile planning approaches and limiting the project financing multiplier. If a KuU event occurs in one location, the system can be maintained in the alternative location to maintain continuity.

ii) Resistance: plan for the most pessimistic future scenario. Implementing safety barriers: A simple real estate approach is to standardise terminology and reporting processes. This one framework toolset and single vocabulary can improve knowledge sharing across multinational real estate organisations.

iii) Resilience: make the assurance of recovery after a future occurrence. Global real estate partnerships can create operational teams that transcend geographic and temporal boundaries and so provide ideally flexibility with lower costs. The shared information is also advantageous with improved management knowledge.

In conditions of uncertainty, an interrelated strategy of adaption, resistance and resilience can reduce the impact and provide a response to KuU events. These three overlapping (not mutually exclusive) approaches can reduce vulnerability and offer improved certainty across the identified risk spectrum. This conceptual framework offers real estate decision makers an opportunity to succeed in a world affected by 
increasingly large, highly improbable and unpredictable events where unprepared competing real estate operations will fail.

\subsection{Conclusions}

Real estate practitioners should be aware of the existence and distinction of $\mathrm{K}, \mathrm{u}$ and $\mathrm{U}$ risks, as $\mathrm{K}$ risks provide certainty through the available data and are often amenable to statistical treatment (e.g. Y2000 computer bug); u events are the most common quantifiable situations, but the time and location may be unknown (e.g. earthquakes); whereas the $U$ risks are difficult or impossible to model (e.g. asteroid showers). In addition to the three categories of uncertainty, the fourth category is unknown knowns, whereby uncertainty is quantifiable but without data available to authenticate or substantiate.

Classification of the four classes of uncertainty can be based on the possible model/data combination by deconstructing into its constituent parts, model/no model, data/no data. Furthermore, the KuU paradigm can envision both as a measurement and a theory. Knowledge, as a measurement approach, focusses on measuring possible outcomes with associated probabilities aided by better data and better econometric models to interpret the data. Whilst knowledge as theory focusses on the conceptual model that helps to understand the underlying structure of the phenomenon.

In understanding $\mathrm{KuU}$ risks, it is evident that real estate decision makers are provided with contradictory information. In the past there was an argument to disregard the type of risk and convert them all into assessed risks, with identified events and assigned probabilities. However, the risk management research agenda suggests there should be more focus on lessening the vulnerability beyond the quantitative forecasting judgements, as to anticipate low-probability, high-impact events. A framework that includes adaption, resistance and resilience can significantly assist in managing these risk events. If overlooked, adverse risk exposure can have a major consequence and ruin many real estate decisions.

\subsection{REFERENCES}

Bardhan, A. \& Edelstein, R. H. 2010. Real estate through the ages: The known, the unknown, and the unknowable. In: Francis, X. D., Neil, A. D. \& Richard, J. H. (eds.) The Known, the Unknown, and the Unknowable in Financial Risk Management: Measurement and Theory Advancing Practice. Princeton University Press: Princeton.

Bernstein, P. L. 1996. Against the Gods: the remarkable story of risk, New York, John Wiley\& Sons.

Bralver, C. N. \& Borge, D. 2010. Managing increased capital markets intensity. In: Diebold, F. X., Doherty, N. A. \& Herring, R. J. (eds.) The Known, the Unknown, and the Unknowable in Financial Risk Management: Measurement and Theory Advancing Practice. Princeton: Princeton University Press.

Buhl, H. U. 2012. The contribution of business and information systems engineering to the early recognition and avoidance of "Black Swans" in IT projects. Business \& Information Systems Engineering, 4, 55-59. 
Casti, J. 2011. Four faces of tomorrow [Online]. Laxenburg: OECD. Available: http://www.oecd.org/governance/risk/46890038.pdf [Accessed 15 November 2016].

Daase, C. \& Kessler, O. 2007. Knowns and unknowns in the 'War on Terror': Uncertainty and the political construction of danger. Security Dialogue, 38, 411-434.

Diebold, F. X., Doherty, N. A. \& Herring, R. 2010. The known, the unknown, and the unknowable in financial risk management : measurement and theory advancing practice, Princeton, N.J., Princeton University Press.

Edwards, P. \& Bowen, P. 2013. Risk management in project organisations, Oxford, Butterworth Heinemann.

Evans, D. 2012. Risk Intelligence How to Live with Uncertainty, London, Atlantic Books Ltd.

Flyvbjerg, B. \& Budzier, A. 2011. Why your IT project may be riskier than you think. Harvard Business Review, 89, 601-603.

Granger, C. W. J. 2010. Risk: A Decision Maker's Perspective. In: Diebold, F. X., Doherty, N. A. \& Herring, R. J. (eds.) The Known, the Unknown, and the Unknowable in Financial Risk Management: Measurement and Theory Advancing Practice.

Princeton: Princeton University Press.

Higgins, D. 2015. Black swan events and property asset management: Redefining place and space on global organisations property decisions ESREL 2015: 25th European Safety and Reliability Conference. Zurich, Switzerland.

Higgins, D. \& Perera, T. 2016. Corporate real estate antifragility strategy: Beyond probability and resilience. Corporate Real Estate Journal, 5, 226-237.

Makridakis, S., Hogarth, R. M. \& Gaba, A. 2009. Forecasting and uncertainty in the economic and business world. International Journal of Forecasting, 25, 794-812.

Miles, M., Huberman, A. \& Saldana, J., 2013, Qualitative Data Analysis: A Methods Sourcebook, SAGE, California.

O'Roarty, B. 2005. Value added property funds: managing market risk to maximise returns. Australian Property Journal, 38, 608-613.

Paté-Cornell, E. 2012. On "Black Swans" and "Perfect Storms": Risk analysis and management when statistics are not enough. Risk analysis, 32, 1823-1833.

Sikich, G. W. 2010. Are we seen the emergenece of more white swan events? Exploiting new challenges in enterprise risk management [Online]. LOGICAL Management Systems Corp. Available: http://riskarticles.com/wpcontent/uploads/2012/11/Black-Swans-Grey-Swans-White-Swans-Vigilance.pdf [Accessed 11 October 2016].

Snowden, D. 2003. Complex acts of knowing: Paradox and descriptive self-awareness. Bulletin of the American Society for Information Science and Technology, 29, 23-28.

Taleb, N. N. 2008. The Black swan: The impact of the highly improbable, London, Penguin.

Taleb, N. N., Goldstein, D. G. \& Spitznagel, M. W. 2009. The six mistakes executives make in risk management. Harvard Business Review, 87, 78-81. 